\title{
SIMULATING SMALL UNIT MILITARY OPERATIONS WITH AGENT-BASED MODELS OF COMPLEX ADAPTIVE SYSTEMS
}

\author{
Victor Middleton \\ V. E. Middleton Enterprises, LLC. \\ 2356 Whitlock Place \\ Kettering OH 45420 USA
}

\begin{abstract}
This tutorial introduces concepts for modeling small unit combat as complex adaptive systems (CAS). It begins with a "human-centric" view of the individual combatant and small unit operations, which incorporates the concept of the individual as an integrated weapon system, the Warrior System. It addresses representation of situation awareness/situation understanding (SA/SU), and "soft" factors - morale, leadership, training, nationality/ethnicity, through agent-based modeling (ABM). ABM supports exploration of $\mathrm{SA} / \mathrm{SU}$ by allowing each agent an idiosyncratic, perception-based view of the environment, rather than the simulation "god's eye" view of ground truth. Using ABM further supports the view of small unit operations as CAS - dynamically interacting open systems, characterized by "emergence", with non-linear and chaotic behaviors. A critical problem for Warrior Systems analysis is the lack of engineering models of complex integrated systems. ABM/CAS addresses this lack by "growing" or "evolving" engineering models of systems whose complexity resists traditional reductionist approaches.
\end{abstract}

\section{INTRODUCTION}

This tutorial is motivated by changing conceptions of warfare and a concomitant need for new tools to support analysis for such operations. These changes include a greater focus on small unit operations, and requirements to support crisis response operations and other missions less exclusively oriented to conventional combat.

We provide a brief history of how these changes in military operations and the very nature of conflict (or at least our understanding of that nature) have led us to the need for a more "human-centric" view of the individual combatant. The tutorial approach posits the need, widely recognized over the past decade, for a far more robust, and in fact, revolutionary, representation of the behaviors and cognition. Modeling and simulation (M\&S) capabilities in such areas such as information processing and decisionmaking are essential to supporting analysis of today's military operations with their emphasis on asymmetric warfare, network centric warfare and the adroit use of information and information technologies. In this context we discuss situation awareness and situation understanding (SA/SU - some in the DoD analytic community now distinguish between these two, I choose not to in this discussion). We examine the concept of the individual as an integrated weapon system, the "Warrior System". We discuss the increasing importance of the so-called "soft" factors - morale, leadership, training, nationality/ethnicity, factors previously relegated into the "too hard to do box." We present a relatively new paradigm that views small unit military operation as complex adaptive systems (CAS), and that employs agent-based modeling $(\mathrm{ABM})$ tools to enable a simulation experiment-based approach to analysis. The tutorial concludes with a discussion of the different functional elements that must be considered in a combat simulation, and a set of criteria by which to judge such simulations. 


\section{SMALL UNIT OPERATIONS AND THEIR ANALYSIS OVER THE LAST CENTURY}

The last century of military operations represents a migration from an attrition-based view of combat, in which the primary objective of military operations is the destruction of men and materiel, to the current concept of effects-based operations (EBO) (Smith 2002, Deptula 2001), which seeks instead to "control" adversaries, altering their capabilities and strategic influence through the integrated use of force and non-military mechanisms, with heavy reliance on technology to direct and focus firepower to maximize effectiveness with minimum collateral damage.

In 1916 Frederick Lanchester began the analysis of "modern" combat by quantifying the combat attrition process through a series of differential equations in which casualty exchange ratios are dependent on force ratios and relative firepower effectiveness parameters (Taylor 1983). These attrition rate coefficients reflect individual weapon system kill rates, allowing examination of the advantages of force concentration and the relative contribution of different weapons/units, including the value of indirect fires.

In Lanchester's view, "modern" warfare is described as attrition by concentrated forces, as opposed to battles as a collection of two person duels between groups of individuals limited primarily to edged weapons. In "modern" combat the concept of defense shifts from parrying the thrust of contact weapons to the idea of killing your enemy with weapons fire before he can kill you.

World War II saw the use of mathematical techniques to assist in such operational problems as the search for enemy submarines and modeling of air to air combat. These models applied methods from probability and statistics to deal with some of the fundamental uncertainties of combat. This same time period saw the first use of computers in calculating ballistic tables for artillery solutions, and in the years following WW II computers came to dominate modeling and analysis. They also took on an increasingly important role in military operations. During that time models of the physics of the battlefield added more and more detail to describing the accuracy and lethality of weapon systems, as well as the mobility of large platforms. Models of these platforms and their operating environment became the basis for weapon simulations and simulators, and consequently the level of detail needed to adequately represent the interaction of the large, fast moving platforms drove model resolution requirements.

The 80 's saw a growing need to model individual soldiers, fortunately matched by the growing capability of computer power. Not surprisingly, the first attempts at representing individual dismounted combatants was based on the extant models of larger weapon platforms. In essence, the individual was viewed as a small, slow, unarmored tank. This view was sufficient to explore some aspects of tactics and provide a first cut at an explicit representation of the small unit encounter and dismounted close combat.

The 90's began an explosion in technology for the individual, accompanied by the development of the concept of the soldier system (and now the warrior system), which sought to integrate a wealth of new capabilities for the individual into a complex, synergistic, system of systems. These capabilities: sensors, communications, battlefield digitization, navigation, and so forth, have significantly increased the ability of the individual to perceive the environment, to share this perception with others, and to act in concert with others to potentially control the battle space far more than ever before.

\subsection{Human Centric Human Behavior Representation}

In conjunction with the move to the warrior system the military analysis community has been evolving towards a more, "human-centric" view of human behavior representation (HBR) in modeling and simulation. This may seem odd, as one would think the "human" should have already been the focus of HBR, but as described above, the historical approach to modeling the human has been to adapt methodologies originally developed for large weapons platforms. While a tank-like view of the human has some validity for modeling the physics-based aspects of movement, target detection, employment of ballistic projectiles, message transmission and the like, it falls woefully short of describing the complexity of human behavioral response to the dynamics of the battlefield. Such a view is not sufficient to explore the complexities of human behavior essential to adequate representation of the individual.

Tanks and airplanes don't get hot and tired, they don't make decisions influenced by their psychophysiological status, and they are not generally subject to wide variations in performance as functions of 


\section{Middleton}

morale, training, unit cohesion, national characteristics and the host of so called "soft factors" that have long been recognized as key contributors to battlefield outcomes. Representation of these factors requires moving beyond the physics of the battlefield to an understanding of human physiology and psychology. "Good" modeling of the individual must take into account the concept of humans as processors of information that accept inputs (scenarios, environmental conditions, missions) and produce outputs (decisions, actions, mission performance).

The digital battlefield and the evolving military mission space have driven a transition in emphasis from modeling the individual as an actor - characterized by actions (move, shoot, communicate) to modeling him/her as a decision-making entity or unit - one who continually evaluates the battlefield dynamic to decide when, where, and how to move, shoot, and communicate. Making decisions is obviously a function of data, or more properly, of information, which leads to the need to represent the acquisition and processing of data at the level of detail and significance critical to the individual Infantry combatant.

\subsection{The Warrior System and Measuring Its Performance}

The "warrior system" concept seeks to integrate the capabilities of new technologies to forge the individual combatant and his equipment into a complex, synergistic, system of systems. The concept has been through a number of iterations in the US, which have differed far less in concept than in bureaucratic programmatic and cost issues. All of them sought (or still seek) to end the stove-piping of different systems and sub-systems for individual combatant, giving him far more integrated functionality, and, as mentioned in the above quote, recognized the need to treat the individual soldier as a complex weapon system in his own right, as much for programmatic consideration in Congressional funding lines as in fielding new technologies for the soldier.

The warrior system encompasses multiple system capability areas: lethality, survivability, mobility, command and control, and sustainability. To get the resolution required for analysis of this system we must view it as the integration of physiology, psychology, equipment, subsystems and systems. Analysis of this system requires "adding" measures of performance for these "eaches" to reflect the capability of the whole - describing a spectrum of human responses, actions, decisions, and decision outcomes.

The first step in defining the soldier as a system was listing the so called soldier "illities", the soldier capability areas listed above. These are often described as members of a hierarchy or branches of a tree, but they in fact have complex interactions and dependencies within each other, and exploring the nature of these interactions, and indeed, of the capability areas themselves has been the subject of considerable research over the last two decades. Much of this research has been focused on cognitive functions, information processing, and psychological aspects of personnel interactions. The $\mathrm{C}^{2}$ illity, command and control capability, has been expanded into $\mathrm{C}^{4}$ ISR: Command, Control, Communications, Computers, Intelligence, Surveillance and Reconnaissance, and many now consider SA/SU to be a sixth "illity", albeit one closely aligned with $\mathrm{C}^{4} \mathrm{ISR}$.

In 1998 and 99, the author and several colleagues, working as part of the Technology Base Steering Committee's Warrior Systems M\&S Working Group came up with the concept of the "Warrior Systems Architecture" (WSCA) - a sort of "yin and yang synergistic octopus" to better represent the nature of the interplay between the "illities". The version shown here, in Fig. 1, has been updated with the additional factors of basic soldier attributes (both psychological factors such as training, leadership, morale, cultural identity, and physical state factors such as fatigue and heat stress), and mission demands (e.g.; combat intensity, criticality of tasks, and rules of engagement). We were attempting to capture the natural dualities of complementary opposites within a greater whole. For example, there is always tension between mobility and protection - do I want to try to avoid the enemy bullet, or defeat it when it hits me? Ideally I'd like to do both, but the more effective my armor, the more it weighs me down and slows me down, making me easier to hit. C4ISR gear can warn me and allow me to outmaneuver my adversary; does this mean I can afford to reduce my armor? Is the best protection under some circumstances no protection? 


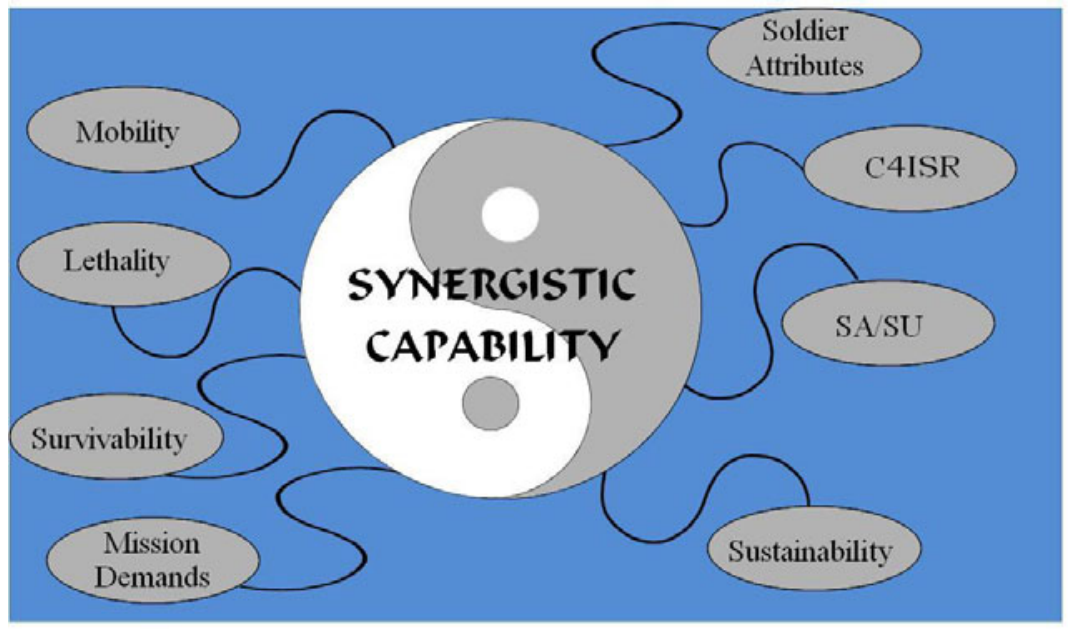

Figure 1. The Synergistic "illity" Octopus

The six capability areas must therefore be dynamically integrated at multiple levels from technology systems to the individual fighter through the fighting element (Middleton et al. 1999).

\subsection{Agent Based Modeling and Complex Adaptive Systems}

Good engineering models exist for vehicle-based weapons systems such as tanks, planes and ships; models that support trade-offs in design development and functional capabilities for these systems. The same is not true for the individual combatant, where the individual IS the weapon system, or at least the most critical component thereof. It is far easier to predict the performance of vehicle-based platforms than that of the individual combatant; the laws of physics describe how fast a plane can fly, allow estimation of the accuracy and lethality of a projectile, and prediction of when a tank will run out of gas. Of course individual combatants are subject to the same physical laws, but when the human is added to the equation, morale and leadership must also be considered, as well as the role of doubt and uncertainty, fatigue, heat stress, hunger and thirst, fear, "and the thousand other shocks that flesh is heir to."

In addition, new and highly sophisticated technologies have increased the firepower and capabilities of the individual soldier, and have dramatically enhanced the capabilities of units at every level for coordinated and focused force projection. Technology also provides the capability for greatly increased operational tempo, demanding accurate SA/SU and rapid decision-making. Further complicating the situation is increasing emphasis on asymmetric conflicts where the application of technology alone may not necessarily be a force multiplier. In such a conflict, the overwhelming fire power and technological advantages of even multi-national forces may be moderated or neutralized by the destructive capabilities available to individuals or small groups of dedicated opponents, especially those who operate outside accepted frameworks of international law and regulation.

The complexity and dynamic nature of small unit combat operations leads naturally to the consideration of such operations as complex adaptive systems. There is no single accepted definition of a CAS, although there is reasonable agreement as to the general characteristics of such a system (Holland 2006, 1992; Waldrop 1992). First, of course, a CAS is a complex system, most often an open system possessed of a high degree of structure, with many components having dynamic interactions. System behavior generally depends not only on current state variables, but also on the history of the system. System relationships and behaviors are frequently highly non-linear and chaotic, meaning they can be highly sensitive to small perturbations in input conditions. System component interactions frequently take the form of adaptive emergent behavior, in which the system coevolves with the environment and other systems. Adaptation is a concept taken from the biological view of evolution and implies the presence of a "fitness" function or functions that support "selection" of those characteristics or behaviors of the system that enable it to best "fit" in its environment. 


\section{Middleton}

In 2004 Andrew Ilachinski of the Center for Naval Analyses wrote Artificial War, perhaps the seminal work on modeling combat as CAS. He, too, traces the development of combat modeling from Lanchester's work to his own agent based models, the Irreducible Semi-Autonomous Adaptive Combat (ISAAC) model and its successor EINSTein, Enhanced ISAAC Neural Simulation Tool (Ilachinski 1997, Ilachinski 2003). These models are characterized as distillation models, which "ideally have the following four characteristics: transparency, speed, ease of configurability to the question at hand, and requirement of little training to use" (Horne \& Leonardi 2001). Other agent based models, such as IWARS and CombatXXI are aimed at a higher resolution treatment of problem space, and therefore provide a much more detailed operational environment with correspondingly richer agent behaviors. Such detail, of course, is not without cost, in simulation execution time, and perhaps more significantly, in the time and resources required for scenario construction.

The distillation models and their more detailed cousins are based on goal-directed agents, sometimes referred to as intelligent agents, that perceive the condition of their environment and select their behaviors to effect changes to that environment. Such agents, also referred to as intelligent autonomous agents, are:

- goal-oriented - able to build courses of action by taking the initiative to change elements of the world state to desired objectives,

- perceptive - able to receive data from their environment, including knowledge of their own state and that of other entities of interest to them,

- active - able to perform actions affecting their environment, and

- autonomous - able to initiate behavior sequences based on internal logic to determine what is appropriate given the perceived environment.

Agents representing combat forces must also generally be:

- mobile - able to move around in their simulated environment,

- capable of inferring the intentions of others, the desires and plans of other agents, and

- social - able to share goals, cooperate with or coerce other agents.

A key distinction between agents that are "intelligent" and those that are merely reactive is the concept of maintaining a perceived view of the environment, having "knowledge" of the world based on current and historical data from the agent's sensory input capabilities. Intelligent agents are not omniscient, they do not share the simulation "god's eye" view of the world, rather they gather and interpret data according to their own capabilities. One can characterize the degree of an agent's intelligence based on the extent of its historical sensory database, its capability to use inference to supplement incomplete input data, and/or to resolve uncertain or inconsistent data, and its degree of autonomy. Autonomy is gauged by the degree to which behaviors are not pre-scripted by simulation designers; the options available to the agent in response to the perceived environment and the flexibility the agent has in choosing those options. It may be somewhat ironic that agent-based models, as with the theory of CAS that is their foundation, focus on relatively simple interaction rules to achieve their complexity. Such rules direct how simulation agents deal with each other and their environment. Fortunately, given the multitude of theories of human performance, these rules need only be internally consistent; they do not require a single unified theory of human behavior. In fact, an ABM approach can embrace multiple rule sets, some of which may be based on competing, and even contradictory, social science theories and data. This multi-disciplinary approach supports representation of individuals with widely diverging belief systems and standards of behavior, a virtual necessity in accommodating the clash of cultures that characterizes the human dimension in much of today's military operations.

Agent-based modeling is not a major divergence from popular simulation approaches such as discrete event simulations and systems dynamics. Rather it builds on top of these tools, and any comprehensive combat simulation will incorporate elements of all of these tools. For example, many of them are clock driven simulations that maintain lists of scheduled events, and use Monte Carlo draws to determine the outcome of stochastic processes, while also using closed form equations to calculate deterministic results. 


\section{Middleton}

Viewing combat as CAS may lead to an engineering model of the Warrior System as a compromise, between top-down, reductionist approaches to $M \& S$, and the use of bottom-up synthesis - "growing" or "evolving" models of systems whose complexity resists traditional reductionist approaches.

The reductionist approach decomposes well-understood phenomena into component pieces until an appropriate level of fidelity is reached. For example, the typical "two-person duel" engagement process can be broken down to target acquisition, weapon operation, and damage assessment. These functions can be further decomposed into detection, recognition, and identification, weapon aim and operation, projectile fly-out, projectile impact, and so on.

The reductionist approach works best when conditions (expressed as state variables for the objects involved) are relatively static. When conditions become more dynamic, the assumption of independence of the functional modules (necessary for the reductionist approach) is violated. For example, if a target is detected, but acquisition is lost prior to weapon fire, current models simply restart the acquisition process; ignoring the fact that re-acquisition of a previously known target is very different from the initial search and detection of that same target.

The synthesist approach allows each side to react and adapt to what the other is doing, and has done. Entity interactions provide for both action and reaction, and may be influenced by the history of previous interactions. Of course, there is no rule against including such histories in the reductionist functional breakdown, but such a breakdown soon runs afoul of the combinatorial explosion of sequences of action/interaction possibilities. The agent-based synthesist approach avoids this problem (or at least delays it) by dynamically building its sequences of possible interactions instead of relying on a priori definitions.

\section{MODELING SMALL UNIT COMBAT}

M\&S for small unit combat must address a breadth of applications from research and design to acquisition and fielded operations. This breadth is reflected by the types of questions asked of the modeling simulation and analysis community. Examples that this author has personally encountered include:

- What body armor design best achieves the trade-off between protection and operability?

- What is the recommended basis of issue for Land Warrior and follow-on Ground Soldier Systems? Subsystems? Components?

- What components of the Warrior System give the best return on investment?

- Should (or how should) Tactics, Techniques and Procedures (TTP's) be modified to reflect new capabilities and exploit technology?

- What is the optimal fighting load?

- What are the power requirements for next generation systems? Can they be sustained?

- What are the effects of information technologies on combat outcomes? How can these effects be quantified?

- What are the effects of incremental differences in nutrition, ration scheduling and fatigue on mission effectiveness/completion?

\subsection{M\&S Requirements}

There is no "one size fits all" tool to answer these questions, In June of 2000 John D'Errico, in private communication with this author, provided a set of M\&S requirements for small unit operations. John was then an analyst for the US Army Training and Doctrine Command (TRADOC) System Manager, Soldier (TSM-Soldier), a long-time military OR analyst and retired Infantry officer. His list includes:

- Explicitly acknowledge the roles and contributions of individuals. For example, most models currently treat unit leaders as basically riflemen--if a unit leader is killed, there is no loss to the unit other than the unit leader's weapon.

- Adequately represent Infantry weapons and their employment. For example, employ machine guns in pairs; when an Infantryman is killed, ensure that his weapon and ammunition are still viewed as a 


\section{Middleton}

squad resource, usable by others; mortar rounds, missiles, and other heavy squad or platoon weapons and munitions should be distributed among squad and platoon members, instead of being magically carried by a single Infantryman, or otherwise appear at the destination - it is important to model the soldier's load and the effects of carrying it (or of not having items that may be needed).

- Ensure the ability to model current technologies (lasers, night vision devices, body armor, soldier loads, aiming lights, unmanned aerial vehicles, sound, etc.), as well as potential associated changes in tactics, techniques, and procedures (TTPs) of Infantrymen and Infantry units.

- Provide the capability for multiple combat environments (MOUT, day, night, open field, wooded area). Enhance digital terrain, which up to now in most models which portray Infantry, has typically been of the rolling hills type, rather than the typical Infantry terrain which consists of ditches, bumps, folds in the ground, creek beds, road beds, thick vegetation, wooded areas, tree trunks, deadfall, large rocks or boulders, etc.

- Support differentiation between cover and concealment and allow multiple degrees of each, at present if a person is concealed he usually cannot be seen or engaged--but the concealed person usually becomes blind as well, and is unable to see his enemy either. Concealment often should allow the concealed person to see, without being seen.

- Meet the long unfulfilled requirement for highly detailed, valid, Infantry scenarios at the squad, platoon, and company level, in various military operations. TRADOC standard scenarios do not provide the level of resolution appropriate to modeling the individual Infantry combatant. Those organizations who are in the business of developing models and simulations which include Infantry representations, and developmental organizations which have long needed good, highly detailed scenarios with which to evaluate developmental advances, need valid Infantry scenarios which describe details down to radio calls, movement rates and formations, control measures, tactics, techniques, and procedures.

While this list is by no means exhaustive, it gives a flavor of views widely held in the R\&D community.

\subsection{Defining Small unit Combat through the "illities"}

This section explores each of the "illities" of the Warrior System, their interactions, and their integration into overall system performance. The section describes the use of "illity"-specific measures of performance (MOPs) to generate system-level measures of effectiveness (MOEs). MOPs provide observable, engineering-level measurements, for which data can actually be collected, and which gauge specific performance characteristics, whereas MOEs are quantitative expressions that compare the effectiveness of alternatives in meeting operational objectives or needs, which must generally be calculated or inferred. It is only a slight over-simplification to say that the primary function of M\&S is to turn MOPs into MOEs.

\subsubsection{Lethality}

Lethality is the capability to overwhelm or destroy an adversary, quantified by such MOEs as the loss exchange ratio (LER), the ratio of friendly to enemy casualties (Brady and Starr 2002; Bowley, Castles, and Ryan 2004). This requires estimation of the number of both friendly and enemy casualties, usually aggregated over multiple engagements or battles. Lethality depends on the accuracy of specific weapons or weapon systems, which is usually quantified through such MOPs as probability of hit, probability of incapacitation, and probability of kill. These measures are primarily derived from weapons fire tests, where data such as number of hits and ballistic "dose" at given ranges are collected. Assessment of all the "illities", including lethality, is quite mature with respect to physics-based phenomena - ballistics and weapons effects, target signature propagation, but far less so with respect to cognitive or behavioral phenomena - interpreting environmental data to detect targets, deciding what targets to engage and how to engage them.

As is also the case with the other capability areas, lethality calculations are relatively more mature for powered weapon systems such as tanks and airplanes than they are for the warrior system. Tanks, unlike 


\section{Middleton}

soldiers, can be tested to destruction, so probability of kill given a hit for a tank can be empirically measured under peacetime constraints. The scale on which the individual dismounted combatant operates gives rise to a number of problems not faced by larger, faster moving platforms. Furthermore, the accuracy of the dismounted combatant is far more sensitive to variations in the environment, and to the individual's physiological response to that environment. Tanks do not get tired or scared. Even if the individuals in them do, the steadiness of their aim and their rate of fire do not suffer to same extent as they do in the dismounted individual.

The individual combatant's capability to detect and acquire targets is, of course, a key element of lethality, and one that again is modeled much better for large weapon platforms than it is for the individual. Models that were developed for detection of trucks and tanks have been adapted to consider the dismounted individual, but these models do not account for such factors as dynamically changing posture and attendant signature variations. Perhaps even more importantly, they do not allow any benefit from prior target knowledge and other aspects of SA/SU. Given the high priority of warrior systems sensor programs, better representation of sensor operation and subsequent interpretation of sensor data is another key modeling priority.

The synergisms between survivability, mobility, and lethality, e.g., the ability to use terrain and cover to close on the enemy while minimizing one's own risk, are amplified for the dismounted combatant. At the same time, the degree of environmental resolution (terrain, cultural features) required, and the number of potential responses by the individual to that environment, are enormously higher for the dismounted soldier than for the large weapon platform.

Finally, equating lethality with casualties in assessment of the lethality of the dismounted combatant ignores the complexity of modern military operations. The past two decades have seen a move to missions involving armed interventions short of war, such as peacekeeping, peace enforcement, information warfare, stability and security operations (SASO), and crisis response operations (CRO) (Smith 2002). This move can been referred to as a shift from "close combat" toward "close contact" operations that brings with it the need to augment traditional direct measures of attrition warfare (i.e., the "killer victim scoreboard") to reflect a broader range of mission objectives. Enhancing current analytic tools to encompass these objectives will require development of MOPs and MOEs, for example, measuring levels of "control" of people, places, and/or other militarily or politically significant objects or events (Middleton and Mastroianni 2008).

Assessing lethality as the capability of the military to project and apply this force continuum now requires representing rules of engagement, making judgments as to the appropriate level of force used, and estimating the effects of such use.

It is desirable to estimate the non-lethal effects of even the application of "deadly force", in particular suppression (Middleton, Christenson, and D'Errico 1995). Historically the role of suppressive fire has been a significant factor in overcoming or dominating the enemy. Current M\&S tools represent suppressive effects by using simple "near miss" relationships to force targeted individuals into full or partial defilade. These models do not represent, and hence cannot measure, most of the complex behaviors that constitute suppression. This is one of the areas in which the effects vs. process debate must be decided in terms of much greater definition of the process. Suppression "processes" must consider those battlefield factors or combat stressors which may induce suppression, and represent the translation from the causes of suppression to observable and quantifiable effects.

\subsubsection{Survivability}

Since survivability in combat is essentially the converse of lethality, its representation and measurement has basically the same resolution and fidelity issues. Survivability is, however, further complicated by the need to address environmental hazards, such as heat stress, fatigue and disease, non-battle injuries (DNBI), as well as adversary threats such as chemical and biological weapons whose use is proscribed by US policy. In particular, analysis of current military operations requires consideration of improvised explosive devices (IEDs) and other similar aspects of asymmetric conflict. SA/SU and $\mathrm{C}^{4}$ ISR contribute 


\section{Middleton}

heavily to those elements of survivability where the ability to recognize and avoid or neutralize the threat is as or more important than the ability to shield individuals from its manifestation.

Survivability contributes to improved LER outcomes; the MOEs most historically associated with survivability are reductions in casualty occurrence rates and/or the decrease in the lethal area of selected threat munitions. These MOEs are affected by such factors as the efficacy of body armor in stopping or retarding projectiles and the ability of camouflage or other methods to reduce detection signatures. Armor efficacy is based on either test results or engineering model predictions, and reflected by MOPs such as projectile/fragment retardation coefficients, or percent fragment attenuation; signature reduction is quantified by such MOPs as time to detect, or contrast/sensitivity ratios.

The measurement of survivability as numbers of casualties, or rates of casualty occurrence, is limited by the definition of exactly what constitutes a casualty. Representation of individual combatant casualties is usually restricted to two casualty states: dead or incapacitated. When greater resolution is desired, the model of the individual as the small slow poorly armored tank leads to emulation of the traditional categories of tank damage: mobility kills (injuries to the legs) or firepower kills (injuries to the arms or eyes).

A more robust characterization of ballistic injury effects and operational casualty measures requires a more performance oriented view of casualties, and/or more accurate medical characterizations. The logical conclusion to a performance-oriented view of casualties is a continuum of performance decrements associated with different casualty states or levels of incapacitation, and extension of these decrements to cover environmental hazards, all as part of a comprehensive set of performance moderators that relate human behavior to the psycho-physiological state of the individual.

Fatigue and heat stress have long been recognized as having significant potential for performance decrements, especially as related to the use of chemical protective equipment and body armor (Klopcic 1989; Santee, Matthew, and Tharion 1992; Matthew et al. 2003). At present there are accepted physiological models for heat stress (e.g., USARIEM thermal stress model) and nutrition, e.g., Short et al. (2000), and research is ongoing with respect to other aspects of physiological and cognitive performance (Leiberman et al. 2005; Staal 2004; Institute of Medicine of the National Academies 2004; Wesensten, Belenky, and Balkin 2005; Thomas and Russo 2007).

\subsubsection{Mobility}

Mobility reflects the ability to move and control terrain, as measured by speed and/or distance. Current modeling capability permits definition of individual movement speed in response to such as factors terrain grade and trafficability, with limited consideration of physiological state (as measured by core temperature, max VO2, heart rate, etc.) (Mastroianni and Middleton 1996). Algorithms exist to support dynamic obstacle avoidance and some use of terrain features, and the use of path finding/planning tools such as Dijkstra's algorithm and the A* algorithm are fairly common, e.g., Reece et al. (2000).

Intelligent agents will regulate through self-pacing or in response to command guidance, their speed, movement formations, frequency of rest breaks, and other aspects of dismounted movement, to optimize the trade-offs between energy expenditure, threat avoidance, and mission demands (Middleton and Mastroianni 1996; Mastroianni and Middleton 2001; Middleton, Hennon and Hayes 2002).

A key feature for mobility today is the concept of the network centric force and its employment of global positioning systems (GPS) and Geographic Information Systems (GIS) (Murdock 2002; Mitchell 1999). Again, in order to assess the benefits of these technologies, baselines of imperfect information are required, for example, permitting entities to "get lost" as a response to poor SA/SU, bad decision-making or combination thereof.

Intelligent agents must make use of, and react to, terrain and cultural features, including information not found in traditional terrain databases. Especially of concern is information about environmental features affecting decision-making at dismounted combatant levels of resolution. Current efforts in the US Army's IWARS model development, for example, are addressing this information gap by enhancing data bases to include "semantic" terrain, enhancing the attribute lists of current environmental features and/or creating new terrain artifacts to represent areas of cover and concealment, areas of tactical importance, 


\section{Middleton}

danger areas, choke points, and other militarily relevant elements (Stanzione and Johnson 2006). The information provided by such attributes would be typically known to a human observer, but not easily inferred by an autonomous agent in a constructive simulation. The benefits of augmenting terrain with these data include more robust adversary behaviors in training simulators and more robust modeling of intelligent agents on all sides in constructive simulations.

\subsubsection{Sustainability}

Sustainability of the Warrior System requires ensuring maintenance and/or re-supply of adequate resources to perform mission tasks. These resources include the obvious - food, water, ammunition, power, shelter - but also extend to such things as sleep and psychological and physiological conditioning. For warrior systems analysis, sustainability issues fall into three broad categories:

- Mission requirements - needs for each individual and the unit as a whole to accomplish the mission. Deciding on requirements and priorities is commander's responsibility and involves the judgment of the commander on the scene. This individual must weigh risks and rewards, evaluate probable needs and critical failure points, making a subjective assessment of how much of what the troops will need to carry out their mission.

- Logistics - ensuring the individual and unit have what they need when they need it, which can encompass all aspects of military operations dealing with materiel and services, from research and development through acquisition, to storage, movement, distribution, and maintenance

- Soldier's load - as stated above, the load question is not really about how much the soldier can/should carry, but what. As a rough rule of thumb, the average fit individual can carry about $30 \%$ of his/her body weight more or less indefinitely without significant performance decrement. After that performance problems (e.g.; reduced movement speed, increased fatigue, decreased firing rate/accuracy, ability to comprehend and react to threats) begin to kick in, until at around $50 \%$ of body weight a practical upper limit is reached.

Logistics remain a key concern in the planning for any military operation (Mongilutz, 1997; Douglas, Downing, and Steele, 2001; Jones 2006; James 2009). Sustainment issues at the small unit level remain focused on rates of expenditure of ammunition, food, water, and now, power. The network-centric force and the warrior system bring a much-heightened consideration of power requirements, adding "bullets or batteries" to soldier load options. Estimation of mission-specific power requirements brings with it the standard utility vs cost trade-offs. Operationally, cost is measured primarily in bulk and weight; utility is harder to define, requiring for example, assessment of the value of network centric information, which is at its core an issue of the value of SA/SU.

\subsubsection{C ${ }^{4}$ ISR}

Representation of $\mathrm{C}^{4}$ ISR in M\&S is far and away the least mature of the original "illities". Much work remains to be done in development of MOPs and MOEs for $\mathrm{C}^{4} \mathrm{ISR}$, in part because command and control is far more conceptual than physical. Unlike the other "illities" command and control does not lend itself to treatment with physics-based models. It is closely connected SA/SU, another elusive "I know it when I see it" concept more amenable to qualitative than quantitative measures.

Representation of $\mathrm{C}^{4} \mathrm{ISR}$ requires a model of what the individual thinks/perceives the environment is, and a methodology that translates the individual's perceptions into a resultant set of behaviors. "Perception" modeling addresses the "communication, computers, intelligence, surveillance and reconnaissance" elements of $\mathrm{C}^{4} \mathrm{ISR}$, reflected in such factors as data flow rate, attentional demands, data filtration and fusion processes. It must incorporate physical data acquisition processes such as vision and line-of-sight, auditory localization, tactile/haptic response, and other sensory functions.

While there are models of communications and message traffic in terms of signal transmission, communications network functions and the like, there are no good models of the filtration and fusion of data from multiple sources into information, and the interchange of this information, its flow up, down and laterally within the command structure. Even more critically, there is little concern with the effects of mes- 


\section{Middleton}

sage traffic - what does the small unit commander and/or the individual combatant do with the transmitted data. Realistic modeling of the dynamic confusion and chaos of a "Blackhawk Down" scenario is a significant challenge to current modeling capability.

Current information technologies must address both data fusion and filtration to support the levels of situation awareness appropriate to different echelons of combat, with the small unit (e.g., squads) level providing perhaps the most interesting combination of both command direction and the cooperative coordination of individuals.

Comprehensive $\mathrm{C}^{4}$ ISR representation must integrate physical representations of signal propagation with models of decision-making and inference from uncertain data. Such representation must address key $\mathrm{C}^{4} \mathrm{ISR}$ issues of data fusion and filtration, the desirability/necessity for redundancy, and how to deal with incomplete, late, and/or inconsistent message traffic. It must support both vertical (up and down the echelons of command) and lateral (intra-unit) information requirements. It must address the need for new measures of performance (MOPs) and measure of effectiveness (MOEs) to evaluate $\mathrm{C}^{4}$ ISR systems capabilities and assess the impacts of such improvements on mission accomplishment.

\subsubsection{Situation Awareness/Situation Understanding}

Of all the "illities", SA/SU is the most hypothetical construct. SA/SU is not a "thing" that can be easily measured, like speed, numbers of casualties or even temperature, which while it can't be "seen", still admits to sensible (if arbitrary) ways to measure and express it. Temperature also responds in a reliable and predictable way to specific manipulations. SA/SU is more akin to a construct like intelligence, which is defined mainly by the instrument used to measure it. There is still controversy (after decades of research and study) as to whether there is such a thing as generalized intelligence. Most people think that what is intelligence is really a complex constellation of traits, abilities, experiences, and knowledge. What one thinks about intelligence depends a lot on what one chooses to include in the definition and how one decides to measure it.

The four best known theories relating to SA/SU are Endsley's three elements (perception, understanding and projection) of SA (Endsley 1995); John Boyd's Observe, Orient, Decide and Act (OODA) loop (Boyd 1986, 1987); the Joint Director's of the Labs (JDL) Data Fusion Model (Llinas et al. 2004), and the Dynamic Model of Situated Cognition (Miller and Shattuck 2004, 2006). All of these support a view as an iterative process of data input, data assessment, decision-making and action. This view serves as a basis for simulation of SA/SU in agent-based modeling, and actually reflects back on the aptness of Adam's (1993) definition "knowing what is going on so I can figure out what to do." If, as suggested by Breton and Rousseau (2003), measurement tools "focus on the extra benefits a hyperproficient agent can get", then SA/SU effects should be measurable in simulation experiments that compare such agents to less proficient agents. Fortunately, a simulation designer can develop agents at virtually any level of proficiency, given, of course, a framework and model constructs for representing that proficiency.

\subsection{Terms of Reference}

Finally, I would like to leave the reader a framework to evaluate M\&S tools for small unit combat. I do so as set of terms of reference. The list given here was originally developed by the author and Dr. George Mastroianni in 1996, for a Defense Modeling and Simulation Office (DMSO) conference on dismounted combatant models. They have been somewhat updated for this document and reflect many of the factors software designers must take into account in developing models of small unit operations.

Model Architecture: Is the model event-driven, clock-driven or a hybrid? Is it agent-based or a task network model? Does it have built-in input/output support utilities? How are individual/ unit missions assigned and course of action (COA) alternatives generated and decided on? How dynamically reactive are these COAs, i.e.; to what extent can model entities change their approach to mission tasking based on changes in the battlefield situation? What do individuals know about the enemy situation?

Perception v. reality: Does the model assume an individual has perfect knowledge of the environment? For example, does the model allow the individuals to get lost or to misidentify/engage friendly 


\section{Middleton}

units? Does it provide the individual perfect knowledge of battle damage and casualties? Or does the model maintain an individual's perceived view of the world, the degree to which this perception differs from reality, and how the dynamic processes of data acquisition and comprehension interact?

Knowledge structures \& Decision-making: Does the model have the capability to represent incomplete or inconsistent or other wise "fuzzy" data, and if so, how? Does it support mental maps, semantic terrain, scripts and other schema? Does it make use of heuristics? How does it represent SA/SU? What kinds of inference methods are supported or contemplated, for example: naturalistic decision-making and/or recognition-primed decision-making; Dempster-Schaefer theory; Bayesian belief networks; fuzzy cognitive maps; and/or any of the other techniques to represent decision-making under uncertainty? Does the model consider any of the capabilities, limitations, and biases characteristic of human decision makers (e.g., learning, fatigue, stress, cognitive style), and if so, how?

Command and Control: What, if any, support for automated mission planning, consequence management, crisis management and attendant dynamic adjustment of plans is in or contemplated for the model? Does it represent command and control to the level of the individual? What sources of data does the individual have to determine the changing battle situation, and what kinds of task/behavioral alternatives are available to respond to changes? How does the model relate behavior to doctrine? Are the command and control structures of adversaries assumed the same as those of US Forces?

Communication: What levels of information exchange (e.g., status reports, explicit mission tasking) are represented and at what echelons of combat (e.g., between individuals, units up and down the chain of command)? How is communication represented at the level of the individual in the model/simulation?

Terrain: What level(s) of terrain resolution/features can be represented the model (e.g., $100 \mathrm{~m}, 10 \mathrm{~m}$, surface type, cultural features and vegetation)? Does it distinguish between "cover" - obstacles that block projectiles, and "concealment"- obstacles that obstruct line of sight? How dynamic is terrain (shell holes, craters, collateral damage to structures, etc.)? What theaters of operation and/or terrain specific mission aspects are supported (e.g., MOUT, jungle, desert)? Does the model include phenomenology effects (e.g., weather, illumination, hydrology, visibility, obscurants, etc.,)? If so, how - as explicit processes, stochastic draw, or as implicit effects (e.g. reducing travel speeds and visibility because it's "raining").

Movement: Does the model distinguish between "movement" - travel from one place to another, and "maneuver" - strategic/ tactical positioning of forces for planned advantages? What kinds of terrain features affect movement - trafficability, cover and/or concealment, obstacles? How are routes selected? How are goal positions selected? Does movement take into account buildings (exterior/interior, points of ingress and egress) and other man-made features, and/or semantic value of features such as areas, routes, positions? Does it support path following, movement in formation, dynamic route adjustment?

Target Acquisition and Engagement: What is the mix of explicit and implicit representation factors in the small arms engagement? Are target detection, recognition, and identification viewed as separate processes or aggregated into a single probability? Does the model support explicit projectile fly-out? Are aiming errors and weapon function errors represented separately? Are errors due to the individual separated from errors inherent in the weapon system? What kinds of indirect weapons are supported, and how? Are Rules of Engagement explicitly represented? Is suppression considered, and if so, how?

Threats: Does the model consider IEDs, Chemical, Biological, and/or Nuclear Weapons? How?

Mission: What military operations are (e.g., MOUT, OOTW, non-lethal, humanitarian) represented? To what level of detail or echelon of command? Are operations broken into discrete tasks? Performed by units, individuals, or a combination? How detailed is task representation? Are casualty evacuation and casualty return to duty represented?

Individual Combatant State: How does the model represent the physiological condition and the psychological status of the individual, those attributes of which may be affected by the battlefield environment, and in turn affect the task performance? Does it represent casualty/injury status, food/sleep deprivation, motivation, training status, skill level? Are injuries instantaneous events or can they happen over time, e.g. can an individual "bleed out" without medical attention? To what extent is there task dependent definition of incapacitation, i.e., can injuries or other state decrements prevent performance of 
some tasks, but not others, or degrade task performance in different degrees depending on the task? Does the model permit stressors/enhancers to affect individual performance, and if so, how? Are there similar constraints for other psychological conditions? Are cultural differences represented, and if so, how?

Dynamic Response: How does the model deal with the ability of the individual to react to battlefield cues by altering current behaviors or initiating new ones, Reactive Response, or interpret the battlefield environment and respond to perceived or anticipated conditions, Proactive Response? Does the model include "reasoning" about the future at any level (e.g., modify planned actions based on such events as the loss of a buddy on the flank)? How? Is behavior in the model triggered by simulated events that would correspond to sensory/perceptual cues (i.e., sounds, sights, smells), or is it caused by cascading events in the simulation architecture (i.e., does a detection event automatically generate a fire event)?

Human-in-the-loop (HITL): does the model support HITL for decision-making and, if so, what kind of knowledge does the human possess (e.g.; "the God's eye view, knowing everything, or limited to specific simulation views), what capability is there to capture and/or replicate HITL decisions?

\subsection{Summary and Concluding Thoughts}

A critical problem for Warrior Systems analysis is the lack of engineering models for that system or for complex integrated systems in general. CAS/ABM can help address this lack by "growing" or "evolving" engineering models of systems whose complexity resists traditional reductionist approaches.

The idea of emergence is perhaps the most important aspect of the CAS/ABM based modeling analytical paradigm. It epitomizes the critical difference between previous approaches and this new paradigm; the difference between reductionism and synthesis. Orthodox analysis is based on a top down reductionist approach where scientific phenomena are decomposed into first principles models based on physics, chemistry, biology and other "hard" sciences. The CAS/ABM paradigm is based on a bottom up approach where complex structures with complex behaviors emerge from agents with simple structures and simple behaviors interact with each other and their environment. As a result, the "emergence" of previously unexpected outcomes is almost the norm for this paradigm, as opposed to the general predictability of more orthodox approaches.

Such orthodox approaches have, however, served the community well; first principles models allow us to predict outcomes based on laws of cause and effect, and thus provide a measure of predictive validity for our models and simulations.

Why, then, should we shift to a new paradigm that does not, in fact, provide us the comfort of such predictive validity? In general, M\&S fulfills two primary functions: prediction and understanding, but in truth, we have never done a good job of predicting the outcomes of military operations. For many of the phenomena of interest to us, first principles models are simply not adequate. For such phenomena, accurate prediction of outcomes, other than as aggregate probabilities, is simply a bridge too far. The above mentioned soft factors, the human dimension of military operations, lack the first principles models of cause and effect that are the foundation of "validated", "hard" sciences-based models and simulations. Using agent-based models to address these factors does not mean doing away with the concept of scientific rigor, but there is a need to extend the concept of rigor to incorporate a "soft", incremental focus, where increasing levels of correlation correspond to increased acceptance of predictive validity, and where inconsistency can be accepted as evidence of uncertainty rather than outright error (Middleton and Mastroianni 2008).

The new paradigm represents a shift in analytical focus, from using laboratory experimentation as hypothesis and test, towards using simulation experiments for exploration and discovery. Note that this is precisely the aim of data farming and data mining, which use such experiments to generate mass quantities of data, trolling these data for patterns, trends, insight and meaning. As in much of science, we begin with induction and correlation, from which we hope to infer cause and effect, but must be satisfied with increased understanding, accompanied only loosely by some hope of predictive validity. 


\section{REFERENCES}

Adam, E. C. 1993. Fighter cockpits of the future. In Proceedings of the 12th IEEE/AIAA Digital Avionics Systems Conference. 318-323.

Bowley, D.K., T.D. Castles, and A. Ryan. 2004. Attrition and suppression: defining the nature of close combat. DSTO-TR-1638, Defence Science and Technology Organisation, Australia.

Boyd, J. 1986. Patterns of conflict. Unpublished briefing, Defence and the National Interest. Available via <http://www.dnipogo.org/boyd/patterns.ppt> [accessed October 3, 2010].

Boyd, J. 1987. A discourse on winning and losing. Maxwell AFB, AL: Air University Library, Document No. M-U43947, unpublished collection of briefing slides.

Brady, E., and S. Starr. 2002. Re-assessing dismounted operations in complex terrain using the NATO CoBP for C2 assessment. In Proeedings of the RTO SAS Symposium on Analysis of the Military Effectiveness of Future C2 Concepts and Systems. NC3A, The Hague, Netherlands, RTO-MP-117.

Breton, R., and R. Rousseau. 2003. Situation Awareness: A review of the concept and its measurement, DRDC Valcartier TR-2001-220, Defence Research Establishment.

Deptula, D. 2001. Effects-Based Operations: change in the nature of warfare. Arlington, VA: Aerospace Education Foundation.

Douglas, R., W. Downing, and M. Steele. 2001. The Objective Force Soldier/Soldier Team. Volume I: Executive Summary. Washington, DC: Army Science Board.

Endsley, M. 1995. Toward a theory of situation awareness in dynamic systems. Human Factors: The Journal of the Human Factors and Ergonomics Society 37(1):32-64.

Holland, J. 1992. Complex adaptive systems. Daedalus 121(1):17-30.

Holland, J. 2006. Studying complex adaptive systems. Jrl Syst Sci \& Complexity (2006) 19:1-8.

Horne, G. L., and M. Leonardi, ed. 2001. Maneuver Warfare Science 2001. Defense Automated Printing Service, 1001 Barnett Ave Quantico, VA 22134-5007 USA.

Ilachinski, A. 1997. Irreducible semi-autonomous adaptive combat (ISAAC): an artificial-life approach to land warfare (U), Center for Naval Analyses.

Ilachinski, A. 2003. Exploring self-organized emergence in an agent-based synthetic warfare lab. Kybernetes 32(1).

Institute of Medicine of the National Academies. 2004. Monitoring metabolic status: predicting decrements in physiological and cognitive performance. Washington, D.C: The National Academies Press.

James, C.L. 2009. Riverine Logistics Models: Increasing Combat Effectiveness in the Riverine Group. M.S. Thesis. Marine Corps University. Quantico, Virginia: United States Marine Corps Command and Staff College.

Jones, G. 2006. Transformational logistics within the Infantry Brigade Combat Team (IBCT): solutions or shell game? Fort Leavenworth, Kansas: School of Advanced Military Studies,United States Army Command and General Staff College.

Klopcic, J. T. 1989. The AURA fatigue and heat stress algorithms. Army Ballistic Research Laboratory, Aberdeen Proving Ground, Maryland

Lieberman, H.R., G.P. Bathalon, C.M. Falco, C.A. Morgan 3rd, P.J. Niro, and W.J. Tharion. 2005. The fog of war: decrements in cognitive performance and mood associated with combat-like stress. Aviation, Space, and Environmental Medicine 76:C7-14.

Llinas, J., C. Bowman, G. Rogova, A. Steinberg, E. Waltz, and F. White. 2004. Revisiting the JDL Data Fusion Model II. In Seventh International Conference on Information Fusion, ed. P. Svensson and J. Schubert, 1218-30.

Mastroianni, G.R., and V.E. Middleton. 2001. Where Psychology, Physiology, Biomechanics, and Geography Intersect: Modeling Human Performance. Language, Logic, and Logistics: Modeling and Cross-Disciplinary Discourse. New Mexico State University, Las Cruces, New Mexico. 


\section{Middleton}

Matthew, W. B., L.G. Berlund, W.R. Santee, and R.R. Gonzalez. 2003. USRIEM heat strain model: new algorithms incorporating effect of high terrestrial altitude. Natick, MA: US Army Research Institute of Environmental Medicine.

Middleton, V. E., W.M. Christenson, and J. D'Errico. 1995. Simulation of suppression for the dismounted combatant. In Proceedings of Fifth Conference on Computer Generated Forces and Behavioral Representation. . Orlando, FL: Simulation Interoperability Standards Organization.

Middleton, V.E., C.G. Hennon, T.R. Hayes. 2002. The Next Generation Integrated Unit Simulation System: Intelligent Agent Simulation for Warrior Systems. Eleventh Conference on Computer Generated Forces and Behavior Representation, Orlando FL.

Middleton, V. E., and G.R. Mastroianni. 1996. Using Fuzzy Logic to Model Human Behavior. 64th Military Operations Research Society Symposium. US Army Combined Arms Center; Ft. Leavenworth KS.

Middleton, V. E., and G. Mastroianni. 2008. Implications of human centric modeling for operational analysis. In Proceedings of 2008 Conference on Behavior Representation in Modeling and Simulation (BRIMS). Paper 08-BRIMS-036. Orlando, FL: Simulation Interoperability Standards Organization.

Middleton, V. E., J.A. O'Keefe IV, R.T. McIntyre III, and W.M. Christenson. 1999. Development of the Warrior System Conceptual Architecture (WSCA). In Proceedings of the 8th Computer Generated Forces and Behavioral Representation Conference, Orlando, Florida, May 1999.

Miller, N., and L. Shattuck. 2004. A process model of situated cognition in military command and control. 2004 Command and Control Research and Technology Symposium: The Power of Information Age Concepts and Technologies. San Diego, CA.

Miller, N., and L. Shattuck. 2006. A Dynamic Process Model for the Design and Assessment of Network Centric Systems. 2006 Command and Control Research and Technology Symposium (CCRTS): The State of the Art and the State of the Practice.

Mitchell, A. 1999. The ESRI guide to GIS analysis. Volume 1: Geographic patterns \& relationships. ESRI Press.

Mongilutz, M.J. 1997. Force XXI Logistics: Operational Distribution on the Future Battlefield. Newport, RI: U.S. Naval War Colledge.

Murdock, P. 2002. Principles of War on the Network-Centric Battlefield: Mass and Economy of Force. Parameters: US Army War College Quarterly 32(1):86-95.

Reece, D., M. Kraus, and P. Dumanoir. 2000. Tactical movement planning for individual combatants. In Proceedings of the 9th Conference on Computer Generated Forces and Behavior Representation. Orlando, FL.

Santee, W. M., W.T. Matthew, and W.J. Tharion. 1992. Simulated approach marches during thermal stress: a P2NBC2 study. Technical Report T12-92. Natick, MA: U.S. Army Research Institute of Environmental Medicine

Short, P.M., I.A. Taub, T.J. Doherty, V.E. Middleton, and R.W. Hoyt. 2000. Dynamic Nutrition Model. 22nd Army Science Conference. Baltimore MD.

Smith, E. A. 2002. Effects Based Operations: applying network centric warfare in peace, crisis, and war. Washington, DC: DoD Command and Control Research Program (CCRP).

Staal, M. 2004. Stress, cognition, and human performance: a literature review and conceptual framework. NASA Technical Memorandum 212824.

Stanzione, T., and K. Johnson. 2006. Tools for the Creation of Semantic Information for Modeling and Simulation. Washington, DC: DoD Command and Control Research Program (CCRP).

Taylor, J. 1983. Lanchester models of warfare Vols. 1 \& 2. Operations Research Society of America, Arlington, VA.

Thomas, M., and M. Russo. 2007. Neurocognitive monitors: toward the prevention of cognitive performance decrements and catastrophic failures in the operational environment. Aviation, Space, and Environmental Medicine 78(Supplement 1): B144-B152. 
Waldrop, M. 1992. The Emerging Science at the Edge of Order and Chaos. New York, NY: Simon and Schuster Paperbacks.

Wesensten, N., G. Belenky, and T.J. Balkin. 2005. Cognitive readiness in network-centric operations. Parameters: U.S. Army War College Quarterly 35(1):94-105.

\section{AUTHOR BIOGRAPHY}

V.E. MIDDLETON is an Operations Research Analyst with over 30 years experience developing, implementing, and applying mathematical models and simulations for a wide variety of military and civilian studies and analyses. He has worked extensively in assessment of military chemical and biological defense issues, focusing on balancing operational capability and risk and estimation of human performance in high stress environments. Currently, he is completing in his Ph.D. in Industrial Engineering at Wright State University in Dayton Ohio. His research focus is on the use of intelligent agent technologies to represent situation awareness and other cognitive aspects of individual combatant behaviors. His e-mail address is <middletvewoh.rr. com>. 